\title{
Sirenomelia: A Case Report of a Rare Congenital Anomaly and Review of Literature
}

${ }^{1}$ Mohammad J Khan, ${ }^{2}$ Pallavi Shriram Todase

\begin{abstract}
Sirenomelia, or the Mermaid Syndrome, is a very rare congenital anomaly. It is associated with varying degrees of fusion of lower limb bones, giving them the appearance of a "mermaid." It is almost always associated with other birth defects, such as, renal abnormalities, genital anomalies, and cardiac anomalies. We report a case of sirenomelia associated with bilateral multicystic dysplastic kidneys along with bilateral hydronephrosis, severe oligohydramnios, single umbilical artery, absent anal opening, and absent genitals. To the best of our knowledge, this is the first case to be reported from our region.
\end{abstract}

Keywords: Congenital anomalies, Mermaid Syndrome, Sirenomelia.

How to cite this article: Khan MJ, Todase PS. Sirenomelia: A Case Report of a Rare Congenital Anomaly and Review of Literature. Int J Recent Surg Med Sci 2016;2(1):30-32.

Source of support: Nil

Conflict of interest: None

\section{INTRODUCTION}

Sirenomelia is an extremely rare and invariably fatal ${ }^{1}$ congenital anomaly, with an incidence of approximately 1 in 100,000 live births. ${ }^{2}$ Most of the cases are associated with stillbirth. Only $1 \%$ babies survive the first week of life. It is more common in monozygotic twins than in single births or fraternal twins. ${ }^{3}$ The incidence of male: female affection is 2.7:1. The most characteristic feature is the partial to complete fusion of lower limbs, resembling a mermaid. Associated anomalies make it difficult for the babies to survive; however, there are a few reports of children surviving with the help of operative procedures and treatment. ${ }^{5-10}$

\section{CASE REPORT}

A 25-year-old female, G3P1L1A1, 33 weeks gestation by date, was brought to our hospital for complete placenta

\footnotetext{
${ }^{1}$ Professor and Head, ${ }^{2}$ Assistant Professor

1,2Department of Pediatrics, Government Medical College Chandrapur, Maharashtra, India

Corresponding Author: Pallavi Shriram Todase, G2 Shriramprabhu Apt, Civil Lines, Opp LTV School, Near Zilla Stadium, Chandrapur, Maharashtra, India, Phone: +917020802485/07172252902, e-mail: pallavitodase@yahoo. com
}

previa with severe oligohydramnios. She was not diabetic and had no other chronic pathologies. There was no history of any drug ingestion or any substance abuse. Antenatal USG in the second trimester was suggestive of severe oligohydramnios. A repeat USG in the third trimester showed complete placenta previa, with bilateral multicystic dysplastic kidneys, significant shortening of limbs with a foot not distinctly seen, and a complete cord around the neck. The patient was taken for LSCS in view of placenta praevia with severe oligohydramnios. A $1.103 \mathrm{~kg}$ baby was delivered through LSCS. Apgar score was 2 at 1 and 5 minutes. Resuscitation was given, but the child could not be revived and expired within an hour of birth. The parents were explained regarding the nature of the disease and death, and the baby was handed over to the parents. Postmortem examination was not done.

On examination, the baby was found to have multiple anomalies. There was complete fusion of both the lower limbs with a single foot and fused toes, absent genitals, absent urinary meatus, absent anal opening, single umbilical artery, and a vestigial tail-like structure at the sacrococcygeal area Figs 1 to 3. Other associated

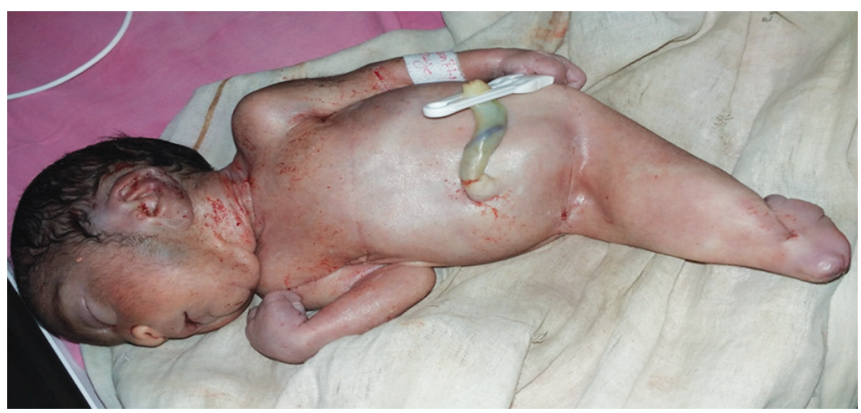

Fig. 1: Single fused lower limb, absent genitals, and absent urinary meatus

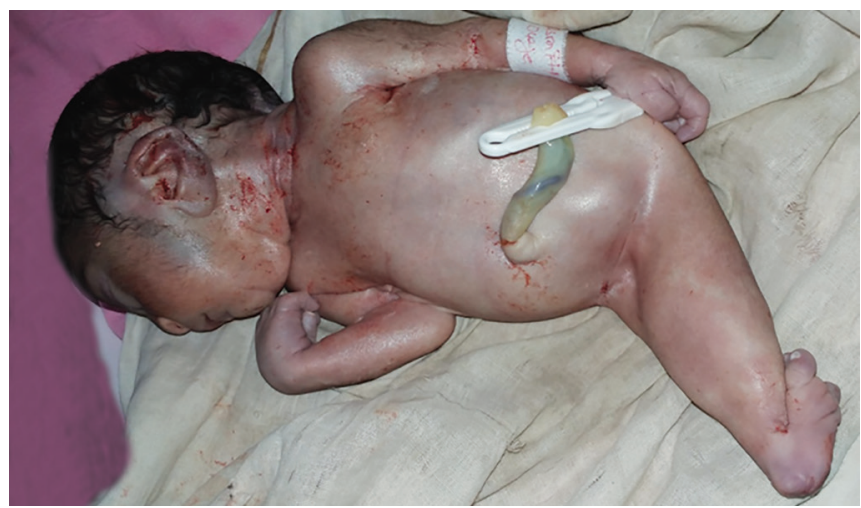

Fig. 2: Anomalous features, such as, single foot and fused toes 


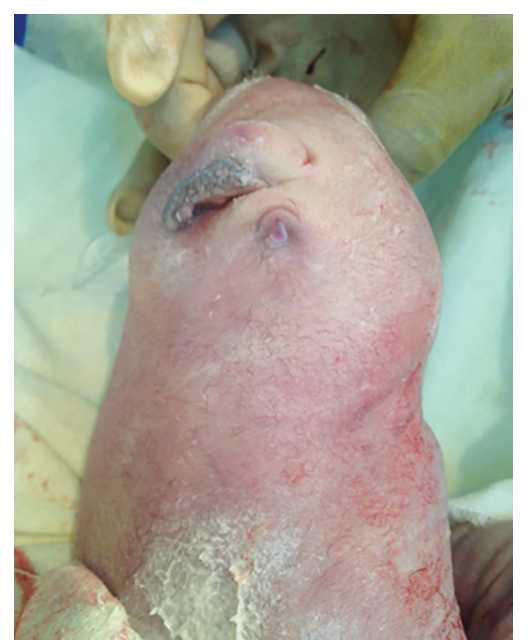

Fig. 3: Vestigial tail-like structure with absent anal opening

syndromic features were microcephaly, hypotelorism, depressed nasal bridge, and low set ears.

\section{DISCUSSION}

Sirenomelia is a rare congenital anomaly involving fusion of varying degrees of the caudal part of the body. Other abnormalities like those of renal, cardiac, pulmonary, gastrointestinal, genital, and nervous system abnormalities are invariably associated with it. The survival depends on the degree of associated anomalies and adequate functioning. We could not ascertain the complete nature of anomalous abnormalities in our child given that postmortem examination was not performed and no imaging was done postnatally.

\section{ETIOLOGY}

There is no single defined etiology, and various theories have been put forth.

Stevenson et $\mathrm{al}^{11}$ proposed a vascular steal phenomenon as the cause of defective development of the lower limbs. According to this theory, there is abnormal perfusion of the caudal portion of the body due to shunting of blood via an abnormal abdominal artery. Due to this, there is inadequate nutrition supply to the caudal part, leaving it susceptible to maldevelopment. Hence, all the structures present caudally are abnormally developed.

Another theory suggests that there is a defect in the later stages of gastrulation during the third week of gestation, which leads to defective development of the caudal parts of the body to varying degrees. This is referred to as the blastogenesis theory. According to this theory, sirenomelia is considered as an extreme form of caudal regression syndrome. ${ }^{12-15}$ However, recent views negate this, and sirenomelia is considered to be a different entity.

Advances in genetics have put forth a genetic possibility for this disease. According to a study by GarridoAllepuz et al $^{16}$ mice lacking Cyp26a1, an enzyme degrading retinoic acid, and reduced bone morphogenetic protein (Bmp) may lead to sirenomelia.

Teratogens, such as, diabetes, tobacco exposure, or drug abuse, also have been postulated to be a cause of sirenomelia.

\section{CLASSIFICATION}

Stocker and Heifet $\mathrm{z}^{17}$ have classified the entity into seven types as follows (Table 1):

Table 1: Classification by Stocker and Heifetz

\begin{tabular}{ll}
\hline Type & Characteristic \\
\hline I & All thigh and leg bones are present \\
II & Single fibula \\
III & Absent fibula \\
IV & Partially fused femurs, fused fibulae \\
V & Partially fused femurs \\
VI & Single femur, single tibia \\
VII & Single femur, absent tibia \\
\hline
\end{tabular}

\begin{tabular}{|c|c|c|c|c|c|c|}
\hline Type I & Type II & Type III & Type IV & Type V & Type VI & Type VII \\
\hline & & & & \\
\hline
\end{tabular}


In our case, no specific classification could be defined as radiographs were not taken.

\section{DIAGNOSIS}

Antenatal USGs are of utmost help in determining the presence of this disease. It may detect abnormal caudal development, such as, absent femurs, tibia or fibula, converging bones, abnormal renal development, such as, renal agenesis, hydronephrosis, absent bladder, and oligohydramnios, which may give a clue to the diagnosis. However, oligohydramnios may restrict the complete evaluation of the fetus. Since there is absence of any open anomaly, alpha fetoprotein evaluation is of seldom help. Previous affected conception may also help in diagnosing the disease. Post-delivery, clinical evaluation is useful for diagnosing this entity. Supportive evidence in the form of ultrasonography and X-rays may also help in diagnosing the extent of associated anomalies. A postmortem examination can also help in determining the nature and severity of the anomalies.

\section{MANAGEMENT AND PROGNOSIS}

Sirenomelia carries a very poor prognosis. The affected babies rarely survive beyond 5 days. ${ }^{17}$ Survival depends upon the severity of associated anomalies. If diagnosed early in the antenatal period, medical termination of pregnancy is advised depending upon the gestational age, extent of anomalies, and approval of parents. However, there are reports of a few babies surviving with the help of surgeries. ${ }^{5-8}$ However, financial constraints, the availability of expertise for treatment, familial motivation, and quality of life post the procedure are issues.

\section{CONCLUSION}

Sirenomelia is a rare fatal congenital anomaly associated with varying degrees of visceral defects. The etiology is still a matter of controversy and is not clearly defined. Antenatal diagnosis is possible with the help of radiology. A regular antenatal checkup, hence, is essential for all pregnant females.

\section{REFERENCES}

1. Taori KB, Mitra K, Ghonga NP, et al. Sirenomelia sequence (mermaid): Report of three cases. Ind J Radiol Imag 2002;12: 399-401.

2. Martinez-Frias ML, Garcia A, Bermejo E. Cyclopia and sirenomelia in a liveborn infant. J Med Genet 1998 Mar;35(3):263-264

3. Sammons MB. Shiloh pepin: the mermaid girl. [Last accessed on 2009]. Available from: http://www.aolhealth.com/health/ mermaid-syndrome.

4. Valenzano M, Paoletti R, Rossi A, Farinini D, Garlaschi G, Fulcheri E. Sirenomelia. Pathological features, antenatal ultrasonographic clues, and a review of current embryogenic theories. Hum Reprod Update 1999 Jan-Feb;5(1):82-86.

5. Savader SJ, Savader BL, Clark RA. Sirenomelia without Potter syndrome: MR characteristics. J Comput Assist Tomogr 1989 Jul-Aug;13(4):689-691.

6. Murphy JJ, Fraser GC, Blair GK. Sirenomelia: case of the surviving mermaid. J Pediatr Surg 1992 Oct;27(10):1265-1268.

7. Clarke LA, Stringer DA, Fraser GC, Yong SL. Long term survival of an infant with sirenomelia. Am J Med Genet 1993 Feb;45(3):292-296.

8. McCoy MC, Chescheir NC, Kuller JA, Altman GC, Flannagan LM. A fetus with sirenomelia, omphalocele, and meningomyelocele, but normal kidneys. Teratology 1994 Aug;50(2):168-171.

10. Stanton MP, Penington EC, Hutson JM. A surviving infant with sirenomelia (Mermaid syndrome) associated with absent bladder. J Pediatr Surg 2003 Aug;38(8):1266-1268.

11. Stevenson RE, Jones KL, Phelan MC, Jones MC, Barr M Jr, Clericuzio C, Harley RA, Benirschke K. Vascular steal: the pathogenic mechanism producing sirenomelia and associated defects of the viscera and soft tissues. Pediatrics 1986 Sep;78(3):451-457.

12. Opitz JM, Zanni G, Reynolds JF, Jr, Gilbert-Barness E. Defects of blastogenesis. Am J Med Genet 2002;115(4):269-286.

13. Thottungal AD, Charles AK, Dickinson JE, Bower C. Caudal dysgenesis and sirenomelia-single centre experience suggests common pathogenic basis. Am J Med Genet A 2010 Oct; 152A(10):2578-2587.

14. Duesterhoeft SM, Ernst LM, Siebert JR, Kapur RP. Five cases of caudal regression with an aberrant abdominal umbilical artery: Further support for a caudal regression-sirenomelia spectrum. Am J Med Genet A 2007 Dec;143A(24):3175-3184.

15. Duhamel B. From the mermaid to anal imperforation: The syndrome of caudal regression. Arch Dis Child 1961 Apr;36(186):152-155.

16. Garrido-Allepuz C, Haro E, Gonzalez-Lamuno D, MartinezFrias ML, Bertocchini F, Ros MA. A clinical and experimental overview of sirenomelia: insight into the mechanisms of congenital limb malformations. Dis Model Mech 2011 May;4(3):289-299.

17. Stocker JT, Heifetz SA. Sirenomelia: A morphological study of 33 cases and review of the literature. Perspect Pediatr Pathol 1987:10:7-50. 